\title{
Infarma - Ciências Farmacêuticas a caminho da consolidação na área das Ciências Farmacêuticas
}

\author{
Infarma - Ciências Farmacêuticas on the way to consolidation in the \\ area of Pharmaceutical Sciences
}

\author{
Anselmo Gomes de OLIVEIRA; \\ Dâmaris SILVEIRA \\ Editores-chefe
}

Ainda no decorrer de uma pandemia que assola todos os países, uma questão que surpreendeu o mundo foi a atuação frenética de grupos de cientistas na busca rápida de respostas científicas para propor soluções aos problemas que se apresentaram. Toda esta pesquisa levou à compreensão de grande parte dos agravos provocados pela COVID-19 e do desenvolvimento de vacinas as quais têm permitido reduzir os casos de contaminação e de óbitos, proporcionando novas esperanças de retorno à uma rotina semelhante àquela de dois anos atrás. Paralelamente, grupos de pesquisa têm se dedicado à investigação em outras frentes, também essenciais ao desenvolvimento científico e, mesmo com a redução de recursos destinados à Pesquisa \& Desenvolvimento, os resultados têm sido visíveis nos vários periódicos que disseminam os achados científicos.

Os temas abordados nesse fascículo, configuram um passeio atrativo no campo do conhecimento da área das Ciências Farmacêuticas e suas tendências. Os artigos trazem abordagens relevantes, tais como a importância indicadores de qualidade no laboratório clínico; a gestão de medicamentos para pessoas idosas em estruturas residenciais, visando a promoção do envelhecimento saudável, assegurando as diretrizes regulamentares na garantia da qualidade e eficácia desses medicamentos; os benefícios da aromaterapia com óleo essencial de lavanda na amenização das diferentes fases vivenciadas por mulheres na menopausa; a aplicação de ferramentas da qualidade exemplificada por um estudo de caso visando identificar a causa da falta de integridade de comprimidos numa indústria farmacêutica, e a avaliação em pacientes portadores de diabetes mellitus tipo 2, atendidos em uma Farmácia Municipal, explorando os registros da intervenção farmacêutica e o monitoramento periódico desses atendimentos.

Assim, com esse fascículo de InfarmaCiências Farmacêuticas encerramos as atividades de 2021, ainda um ano atípico de muito trabalho, mas compensador. Parte do trabalho foi dedicada a reformas estruturais voltadas ao aperfeiçoamento do gerenciamento online das submissões de artigos, à consolidação de uma equipe de 10 Editores Associados e 33 pesquisadores do corpo editorial com representantes nacionais e internacionais distribuídos na amplitude das áreas das Ciências Farmacêuticas. A contribuição dos Editores Associados, sempre pautada na responsabilidade ética das submissões e o apoio inestimável dos revisores ad hoc que disponibilizaram seu tempo precioso na avaliação muito criteriosa dos textos de cada artigo publicado, merecem nosso reconhecimento e agradecimento irrestritos, pois garantiram o fluxo normal da tramitação dos artigos submetidos.

Expressamos nossos agradecimentos sinceros aos autores e coautores, nossos colaboradores diretos, que confiaram os resultados de seus trabalhos ao periódico Infarma - Ciências Farmacêuticas, e esperamos continuar merecendo essa confiança tanto num futuro próximo quanto distante. Os artigos publicados são re- 
presentativos das várias regiões demográficas do Brasil e também do exterior e expressam a criatividade das vocações locais de nossos colaboradores.

Finalmente, os editores do periódico e o Conselho Federal de Farmácia agradecem aos leitores que prestigiam as contribuições científicas aqui publicadas em toda a sua diversidade, e que contribuem decisivamente para a consolidação de Infarma-Ciências Farmacêuticas como um veículo de propagação científica aberto e acessível.

E que o próximo ano seja marcado pela esperança de dias mais amenos e repletos de paz, prosperidade e desenvolvimento científico contínuo.

\section{REFERÊNCIAS}

1. ONU. Relatório da ONU pede ação urgente para evitar crise de resistência antimicrobiana: Organização das Nações Unidas; 2019 [Available from: https://news.un.org/pt/ story/2019/04/1669901.

2. CDC.Antibiotic/Antimirobial resistance: Centers of Disease Control and Prevention; 2020 [Available from: https://www. cdc.gov/drugresistance/index.html.

3. Zagui GS. Avaliação da multirresistência a antibióticos e produção de ESBL e carbapenemases em bacilos gram-negativos de efluente hospitalar e urbano. Ribeirão Preto: Universidade de São Paulo; 2020.

4. IACG. No time to wait: Securing the future from drug-resistant infections. Interagency Coordination Groupon Antimicrobial Resistance; 2019.

5. WHO. Antibacterial agents in clinical development: an analysis of the antibacterial clinical development pipeline. Genebra: World Health Organization; 2019.

6. BRASIL. Dispõe sobre o controle de medicamentos à base de substâncias classificadas como antimicrobianos, de uso sob prescrição médica, isoladas ou em associação e dá outras providências, (2010).

7. BRASIL. Plano de ação nacional de prevenção e controle da resistência aos antimicrobianos no âmbito da saúde única 2018-2022 (PAN-BR). Brasilia: Ministerio da Saaúde; 2019.28 p.
8. ANVISA. Pandemia pode aumentar o risco de resistência microbiana: Agencia Nacional de Vigilância Sanitária; 2020 [Available from: https:/www.gov.br/anvisa/pt-br/assuntos/ noticias-anvisa/2020/pandemia-pode-aumentar-o-risco-deresistencia-microbiana.

9. Razzaque MS. Exacerbation of antimicrobial resistance: another casualty of the COVID-19 pandemic? Exp Rev Anti-infective Ther 2021;19(8):967-71. DOI: 10.1080/14787210.2021.1865802

10. Mazumder P, Kalamdhad A, Chaminda GGT, Kumar M. Coalescence of co-infection and antimicrobial resistance with SARS-CoV-2 infection: The blues of post-COVID-19 world. Case Studies in Chemical and Environ Enginer. 2021;3:100093. DOI: 10.1016/j.cscee. 2021.100093

11. Lobie TA, Roba AA, Booth JA, Kristiansen KI, Aseffa A, Skarstad K, et al. Antimicrobial resistance: A challenge awaiting the post-COVID-19 era. Int J Infectious Dis. 2021;111:322-5. 10.1016/j.ijid.2021.09.003

12. WHO. World Antimicrobial Awareness Week. 18-20 november 2020: World Health Organization; 2020 [Available from: https:/www.who.int/campaigns/worldantimicrobial-awareness-week/2020. 